Meta

Journal des traducteurs

Translators' Journal

\title{
Absorbing Technology: Translation Pedagogy and Networked-Communication Culture
}

\section{Donna A. Williams}

Volume 48, numéro 3, septembre 2003

Traduction et enseignement

Translation and teaching

URI : https://id.erudit.org/iderudit/007596ar

DOI : https://doi.org/10.7202/007596ar

Aller au sommaire du numéro

Éditeur(s)

Les Presses de l'Université de Montréal

ISSN

0026-0452 (imprimé)

1492-1421 (numérique)

Découvrir la revue

Citer cet article

Williams, D. A. (2003). Absorbing Technology: Translation Pedagogy and Networked-Communication Culture. Meta, 48(3), 361-369.

https://doi.org/10.7202/007596ar
Résumé de l'article

L'étudiant novice entre souvent dans le programme de traduction après avoir passé une bonne partie de sa vie comme internaute actif. Cette expérience a une influence sur ses attentes et donc sur la culture de la classe. Cet article porte sur le modèle de circulation d'information sur Internet, sur l'intérêt d'une pédagogie de la traduction incorporant l'aspect social de nouveaux réseaux de communication ainsi que sur l'importance d'adopter une méthode didactique axée sur l'apprenant. 


\title{
Absorbing Technology: Translation Pedagogy and Networked-Communication Culture
}

\author{
DONNA A. WILLIAMS \\ University of Ottawa, Ottawa, Canada
}

\begin{abstract}
RÉSUMÉ
L'étudiant novice entre souvent dans le programme de traduction après avoir passé une bonne partie de sa vie comme internaute actif. Cette expérience a une influence sur ses attentes et donc sur la culture de la classe. Cet article porte sur le modèle de circulation d'information sur Internet, sur l'intérêt d'une pédagogie de la traduction incorporant l'aspect social de nouveaux réseaux de communication ainsi que sur l'importance d'adopter une méthode didactique axée sur l'apprenant.
\end{abstract}

\section{ABSTRACT}

New translation students have often spent most of their lives using computers and the Internet. Their expectations regarding information accessibility in turn affect the culture of the translation classroom. In this article I examine simple ways of appropriating networked communication for a type of translation teaching that takes into account an Internet-based model of information flow. I also advocate a movement toward studentcentred learning.

\section{MOTS-CLÉS/KEYWORDS}

communication culture, information technology, Internet, translation pedagogy

\section{Introduction: A Social Sea-Change} in the Translation Classroom

House (2001) points out that translation quality assessment is primarily linguistic in nature, but that it also entails social judgement. Likewise, the translation class may focus primarily on linguistic concerns, but is at the same time an interpersonal, communicational event. Over the last decade, networked communications technologies have become ubiquitous in the developed world. Many of the nineteen and twenty year-olds now arriving at Canadian universities have grown up communicating engaging in research and social interaction - using computers and the Internet.

As Umberto Eco (1996) has pointed out, the Internet is an infinite and inexhaustible library. It is characterized by its self-healing, indiscriminate overflow of information, and by the relatively little control exercisable within it over information access or ownership. These characteristics have affected not only how work may be viewed, but also the ways in which we may communicate. This in turn has ramifications for translation teaching, which must integrate the new information technologies into the translation curriculum while simultaneously adjusting to a potential social sea-change in the classroom.

Each year more new translation students enter the first year of their program with a set of general expectations about intellectual property, information flow, and information access that are to some extent affected by the presence of the Internet in 
their lives. Their attitudes and beliefs about engaging in social interaction, and more particularly in work involving research, are thus to some extent based on Internet culture, and represent a notable shift since the school days of all but the most newlyminted translation teachers. The traditional approach to translation pedagogy, which emanates from a linear model of teaching as unidirectional transmission of information, is increasingly inadequate for dealing with these profound changes, the implications of which are both abstract and material.

At least three practical aspects of translation pedagogy are affected by the burgeoning of the networked-communications and information technology that has taken place in the last decade: curriculum, teaching techniques, and classroom culture. Of these three, the first two, curriculum and teaching techniques, have been the subject of much discussion, as programs increasingly include instruction on the use of translators' workstations, translation memories, and machine translation, and as teachers increasingly make use of e-learning in their classes. It is the third, social aspect, which is receiving relatively little attention as we scramble to adjust, despite the fact that the culture developing alongside information technologies is impinging upon the translation classroom. In this article, I argue that this latter fact necessitates a translation-pedagogical response that will entail a movement toward studentcentred organization of class information.

The traditional profile of the desirable candidate for a translation program assumes that the more mature student has an advantage. The more well-read the student, so the reasoning goes, the greater his or her understanding of the source text is likely to be from the outset, and the better the comprehension, the better the translation. Inexperienced, extremely youthful students are less likely to be widely read, to follow the news and current events, and to bring broad background knowledge to their travaux pratiques. Recently, my mainly very youthful (novice, francophone) translation students rendered la guerre du Golfe as "The War of Golf," or "The Golf War" in an in-class translation, making it blindingly obvious how few of them had actually followed the geopolitical events of 1991 at the age of nine or ten. Yet, had they done the exercise at home, where most of them have Internet access, instead of in class, where they were deprived of access, it is probable that most (if not all) of them would have come up with a successful translation using their already considerable Web-research skills. It is furthermore these very same youthful and inexperienced students who now arrive with the greatest social adjustment to the new technologies. ${ }^{1}$

\section{Shifting Paradigms: Lecture Notes, Timed Tests, Course Outlines}

I have noticed what appear to me to be changing attitudes in the students passing through the English (L2) General Translation and the Comparative Stylistics classes that I have taught over the last eight years. I'll take just three recent examples: the way my students now view (a) lecture notes, (b) test-taking, and (c) course outlines. 


\section{Lecture notes}

In my experience as a student at the turn of the last decade (1988-1991), notes used for lecturing to the class were considered by teacher and student alike to be the teacher's exclusively private intellectual property. The teacher had absolute control over students' access to the information in those lecture notes, and said information was offered verbally, one single time per session. It would have been difficult to provide access any other way: the teacher would have had to transcribe (many teachers lectured from handwritten notes) and then photocopy and distribute their notes in class, or put them on reserve at the library. The logistics were such that this sort of distribution was not even considered. Handouts listed only a portion of the information provided during lectures. Students were supposed to take copious notes, capturing as much of each lecture as possible. Students who missed a class were expected to "make up" the resulting gap in their notes themselves, by doing extra reading and by borrowing other students' notes. The physical location and time of the imparting of the course content were thus fixed and inflexible, and the information was almost entirely teacher-centred, teacher-run and teacher-controlled.

This has changed: during the first day of class, my students usually now request confirmation that I will be making my lecture notes available to them in some form during the term. The logistics for doing so have, of course, improved: since I automatically prepare and store my lecture notes on my hard drive, it is a simple matter for me to modify and upload them to the class Web site, or attach them to a classaddressed email. This change in medium and technology makes excluding my students from access to information that could help them learn seem old fashioned if not neglectful, especially since so many other university courses are now posted, in whole or in part, on the Web. Students are being taught to use translation memory, where solutions are not copyrighted and reserved but are instead pooled for general use. So it is entirely in keeping with Web-based communication culture that the boundaries of ownership over my notes have blurred: the Internet has made intellectual property an issue in many places.

\section{Épreuves en temps limité}

The Epreuves en temps limité were also a clearly distinct moment in the classroom, one in which all lecture and discussion was suspended while the students sat silently and wrote their exam. After the neophyte's initiation to ETL etiquette, the rules were never reviewed again.

In my recent experience, it is now no longer unheard of for students to solicit information, during an in-progress timed test, about the meaning of the source text or the adequacy/acceptability of a portion of their draft. This year's crop were a startling example: during the first test, slightly more than half the class, (a full 15 out of the total twenty-nine) approached me with questions, most of which concerned neither the instructions nor the exact wording of the source text. This year, I had to repeat the rules before every test, and I repeatedly refused to answer many queries (having interrupted the first ÉTL to review the rules, after which six more students attempted to elicit similar information). But while their numbers dwindled with each test, a 
core group of students continued to try to obtain information even during the final exam, as if they believed that their "search term" simply had to be correctly worded.

Three things must be made clear here:

1. The high rate of questioning was not due to some technical fault in the presentation of the test, which was the same as it had been for a number of years.

2. None of the performance or content questions was answered: I repeatedly refused to respond to these queries, explaining the instructions only.

3. This was not a "bad" group: these students had the usual mix of abilities, backgrounds, and reactions to classroom constraints and demands.

Nothing seemed to set the persistent questioners apart from the rest of the class. They continued to go against my explicitly formulated requirements for behaviour during timed translation tests, yet they were always polite and pleasant in their demeanour. They were also clearly free of a sense of guilt, and evidently felt that they were doing nothing wrong. They were not members of a misbehaving social clique; their grades and backgrounds and ages were in fact quite disparate. One of them was a top student who was a decade older than the class average (of 20.5 years) and who had taught classes himself as an ESL teacher abroad.

There was only one difference, as far as I could determine: their familiarity with the Internet. The "die-hard five" were the same students who used the class Web site the most, according to the number of postings. They were the ones who, my records show, emailed me most often with questions during the term. I believe that their expectations were affected by their familiarity with the Internet.

Subsequent discussion confirmed that the timed tests had interrupted what they saw as their ("paid-for") right to a constant flow of information, and that they were attempting to repair that information flow out of a desire to continue to learn. This objective, they maintained, outweighed that of attempting to test them against what they saw as an arbitrary norm: they preferred to compete against themselves. This was in sharp contrast to what I experienced as a student: a decade ago norm-referenced testing was apparently more widely accepted.

While not all the members of the class possessed Internet skills to the same degree, most of them, I would argue, shared similar expectations. The presence of these expectations in the classrooms points to a generalized culture: students with less experience of the Internet are still affected by their peers' prevailing attitudes. Socioeconomic disparities among classmates, where some have always had fast computers and high-speed connections while others have not, are less and less reflected in the class attitude as a whole, as the "have-nots" come to share expectations with the "haves." This is, after all, not unlike the socioeconomic disparities among the translation students populating pre-Internet translation classrooms: some had more dictionaries than others, but all expected to use dictionaries, and all who went on to complete the program did so in part because they had developed a set of skills and strategies for using them. So it goes with the chief research tool of the post-Internet translation classroom. If the student culture of the class was now such that my reiteration of the rules for timed tests created dissonance instead of consensus, that would explain why my announcements were treated rather like a banner ad on a Web browser. 


\section{"E-adapted" Course Outlines vs. "Shovelware"}

Like many translation teachers, I have added an e-learning aspect to my courses recently, and one of the first things I discovered as I made the transition was that the traditional course outline/syllabus (with its delivery, in linear order, of such information as general and specific objectives, due dates for assignments, and required-plusrecommended reading) was often seen by anxious students as a less-than-effective overview of the course. This was especially true if the course outline was simply posted as-is (html-coded but otherwise unmodified before posting, or what Web designers refer to unflatteringly as "shovelware") to the class Web site.

In retrospect I see that this was going against what is now a solid convention of posting on-line versions of hard copy in PDF format, designed for easy printing. If you post course materials as PDF files, what you are effectively doing is offering students the option of replacing hard copies that they have lost. If you post course materials in HTML code, you are signalling to students that the document contains extra information. That information does not replace, but supplements, the linear listing of the hard copies made available to the class, ideally by providing hyperlinks to modules of information that create bridges across the lists.

Say, for example, that on the first day of class a course outline is handed out that lists the specific objective "Translate the imparfait using the correct English verb tense for the context." The class schedule then lists the topics and due dates of all the assignments and tests. There is no other link, in the paper copy of the course outline, between the objective and the task. In my experience, it is a good idea to post that course outline with objectives that are hyperlinked to modules containing (a) information on the topic of the objective (for instance, examples illustrating the fact that the imparfait may, depending on the context, be translated as the present or past continuous, the past perfect, the simple past, a modal in the past perfect, or the simple present) and (b) a link from each short example to the bi-text from which it was taken. ${ }^{2}$ Adapting the information architecture of an existing document in this way is, of course, quite time-consuming (at least three hours of preparation for every hour of class).

\section{Information Filters and a Flattened Social Hierarchy}

In sum, then, we are dealing with a new communication culture both inside and outside the translation classroom in which the boundaries of intellectual property are hazy, the potential growth of information is exponential, and access to information is wide open. I have given an example of how students expect constant information flow and will try repairing it if it is interrupted. They also expect to be given the means to filter that information, and can be quite cynical about the usefulness of much of it. Access to information must be maximized, but only so that students can search out and make the best selection.

Social interaction is furthermore extremely democratic. As the often-quoted New Yorker cartoon puts it, "on the Internet, nobody knows you're a dog." Group interaction that takes place on the Web tends to be taken over by dominant personalities to a lesser extent than was pre-Web traditional, face-to-face interaction. Among students engaging in collaborative learning (both on the Internet and during 
group exercises in class) there tend, I notice recently, to be relatively fewer "silverback gorillas" running the show, with the result that the "smart but timid" students have a much greater voice in the course as a whole.

For work involving research that takes place on the Web, filtering information becomes a key cognitive strategy: one automatically assesses (if the welcome page on the Web site does not instantly show) how the networked information on the Web site interacts, and then one selects the best information path for one's purposes. I have suggested one way that this can be applied to translation classes in the above discussion of course outlines.

\section{Specific Expectations}

Students who grow up using computers and the Internet thus increasingly arrive in the translation classroom with new socio-pragmatic skills and cognitive strategies that contribute to the culture of the classroom. The vigour of this paradigm shift makes it difficult to ignore. Translation teachers may well find that their students now specifically expect the following in the classroom:

1. Filtered information, to avoid an overload Teachers traditionally presented students with all the information relevant to the course on the first day of class. Students were automatically at a disadvantage compared to the teacher when it came to knowledge access. Nowadays, students are far more likely to discover source texts for the TPs and ETLs given them; they can collect a mountain of information very quickly at home on their computers. What they want from the teacher is a selection, a sculpting out of the most relevant information from the mass.

2. Modular course information for individual knowledge bases In addition to knowing the linear organization of general and specific objectives for the course, students now expect to be able follow interchangeable, student-steered and student-ordered information packets when studying. Just as most Web pages have an index page or "main menu," a posted syllabus must suggest pathways linking key ideas with key skills. The student expects to be able to create his or her own knowledge base among the key points, deciding on an individualized sequence that fills in gaps in their understanding. Students may also decide to "opt out" of some of the information offered, believing that they either already know it or don't need it. Teachers correcting work done on this basis may find it helpful to remind the student of the location of the information, instead of repeating it or marking down a symbol for it. Thus, instead of writing "VT" (verb tense) in the margin, one might write "T3" (for the text on the translation of the imparfait).

3. Visual delivery of information

Teachers may now often discover to their consternation that their "soft-shoe shuffle," their tried-and-true mix of entertainment and erudition in the lectures they've carefully developed over the years, is being treated as a mere "soundtrack," as students focus on whatever visual display is available. 
4. Hyperlinks with bugs

Internet-influenced communication culture also seems to have a high tolerance for the failed links and various other technical problems that are often called "bugs": students are forgiving of imperfection, and are quite willing to look for ways to "reroute and repair" (see the discussion of timed tests above).

5. Collaboratively accessed information

Students may choose to study collaboratively through email or chat functions (on or off the class Web site), consistent with a constant, non-time/space-constrained flow of information.

6. Individually accessed information

Students may see the course content as a system that they have to learn to "run," rather than as a body of knowledge that they have to acquire.

7. Module-based grading

If the student has successfully "run" the system, the student will expect to get the best grade available for his effort. Students may expect that X amount of work should equal $\mathrm{Y}$ grade, and that the top grade attainable will represent completely correct accessing of the class "system." This will put them at loggerheads with the traditional notion that a grade should represent accomplishment rated against an abstract "universal" standard. Students who have these beliefs and expectations will tend to look askance at norm-referenced testing (in which a student's or a group's performance is compared to that of a hypothetical norm group) as a means of evaluating their progress. I believe that attempts to reverse the "gradeflation" trend may meet with resistance from these students, for whom a pass/fail system would make more sense.

\section{Internet-Based Translation Teaching and the Culture of the Classroom}

Even without the evidence of the above expectations, events often conspire to push university teaching onto the Internet. Part-time lecturers often don't have full-time offices, and students taking four or five courses and working 20-30 hours a week often simply cannot come in to see teachers between the hours of nine and five, when shared offices for lecturers are generally available. The change in medium from overhead projectors to Web sites or mass emailings, and from classroom-only lecture to mixed on-line/in-person teaching - will function more smoothly if certain basic principles are observed: ${ }^{3}$

- Manage student anxiety at beginning of the course with a reassuring overview broken down into modules, with some advance organizers. ${ }^{4}$ E-learning is still labour-intensive teaching: for every hour of teaching time, at least three hours of preparation is usually needed.

- When working on line, promote group interaction and discourage one-on-one interaction with students, which can be intensely repetitive and time-consuming. Address the whole class in reply to one student's emailed question. Encourage students to respond to one another. The only exception, and this must be made clear from the start, is sensitive personal subjects: one must not forget to delete the 
part about the dying grandmother in the mass-emailed reply to single student's question about using the imparfait in a late homework assignment. Based on rather unpleasant personal experience, I now institute an immediate all-out ban on students ever engaging me in Chat, and reiterate (before shutting down my chat client if a student appears on it) the requirement for group interaction. With email or Web postings, you can keep a record of what you've said, and you can repeat answers, as you cannot do with chat. Answers, it should be noted, always have to be repeated: students expect to be able to "surf" back to a piece of information. I try to make sure, when I reply to a question for the first time, that I am ready to cut and paste that explanation into subsequent messages.

- Start "real-time" classes with an acknowledgement of the Internet "events" of the week. Redundant information is a good idea (e.g. due dates reiterated on the Web class schedule and in emails to the class about assignments).

- As an alternative to WebCT (which requires a considerable investment in time that many are not yet willing to make) gather the email addresses of the entire class into a single email folder and "post" documents by emailing them out (announce mailings in class).

- Send everything in the body of the email and do not send attachments, which not all students can open. Most Word or Word Perfect formatting will appear in the body of an email, which is HTML-coded.

- Go to Yahoo groups <http://groups.yahoo.com/> and click on "start a new group" to create a class Web site where the documents are stored for ad libidum retrieval by the students.

- Avoid "screen fatigue": documents should fill only one screen. Try thinking of documents on the screen as "post cards."

\section{Conclusion}

Students give very favorable evaluations of courses when they have a vehicle for, and validation of, their Internet research and collaborative learning skills. In this article I have advocated an approach to translation course information architecture in which the teacher becomes more of a facilitator and less of a gatekeeper, and in which learning becomes more student-centred. Translation students' knowledge and expectations can be appropriated to improve and update translation pedagogy, which will in turn benefit these future members of our profession.

\section{NOTES}

1. Their knowledge of social etiquette on the Internet often outstrips the teacher's own, as teachers will attest, who find themselves dealing with an unexpected real-time chat invitation from a student who appears without warning on the teacher's monitor screen, turning the computer into something akin to a telephone that connects without ringing first. In these situations, it may well be the teacher who is the inexperienced novice, and who may be forgiven for wondering how the students "got into my computer" in the first place.

2. This example is adapted from Durand and Harvey (1992), which is presented in a format quite easily adapted to Web use. This manual is divided into two sections: a first part giving general comparative linguistic principles that are accompanied by short examples, which are linked to the second part of the book, where ST/TT pairs are shown with detailed explanations in footnote format, as follows:

Traduction par ' $b e$ ' [au passé] + 'ing'.

On a recours à cette forme en anglais lorsque l'imparfait dénote un état, constituant souvent le cadre dans lequel se situe une action ponctuelle. 
$\rightarrow$ Une femme regardait la télévision. À un moment, elle a allumé la lumière. (T.3) $\rightarrow$ A woman was watching television. She got up to switch on the light.

(Durand \& Harvey 1992: 96)

Students who turn to "T.3" (Text 3 ) will see the complete bi-text.

The textual resources for imitating this format, in which detailed translation principles are linked to examples embedded in whole texts, are widely available on the government Web sites of officially bilingual countries such as Canada, where large numbers of bilingual texts are posted on-line by the various levels of government. For the purposes of comparing the features of the language, it is not absolutely necessary to know which one is the translated text, providing both are free of formal error.

3. Many of these suggestions are adapted from e-teaching pointers proposed by Dr. Sharon Rich and Adele Woolfe of the University of Western Ontario. Rich and Woolfe have developed Web courseware that constitutes an interesting alternative to WebCT. A demo of their courseware may be viewed at $<$ http://www.edu.uwo.ca/conted $>$.

4. Advance Organizers connect new, unknown information to what the student already knows. Hyperonyms (general terms) are often first featured and then broken down into sub-categories during the teaching. For more on this subject, see Ausubel $(1963,1978)$ and Ausubel et al (1978).

\section{REFERENCES}

Ausubel, D. (1963): The Psychology of Meaningful Verbal Learning, New York, Grune \& Stratton. Ausubel, D. (1978): "In Defense of Advance Organizers: A Reply to the Critics," Review of Educational Research, 48, pp. 251-257.

Ausubel, D., J. Novak, and H. Hanesian (1978): Educational Psychology: A Cognitive View (2nd Ed.), New York, Holt, Rinehart \& Winston.

DeKerckhove, D. (1997): Connected Intelligence: The Arrival of the Web Society, Boston, Somerville House Books.

Durand, M. and M. Harvey (1992): Méthode et pratique du thème anglais, Paris, Dunod.

Eco, U. (1996): “Afterword." In The Future of the Book. Berkeley: U California P, p. 295.

House, J. (2001): “Translation Quality Assessment: Linguistic Description versus Social Evaluation,” Meta, 46-2, pp. 243-257, Special edition: Évaluation: paramètres, méthodes, aspects pédagogiques / Evaluation: Parameters, Methods, Pedagogical Aspects. 